\title{
Prior residency advantage for Atlantic salmon in the wild: effects of habitat quality
}

\author{
Eli Kvingedal $\cdot$ Sigurd Einum
}

Received: 26 August 2010 /Revised: 21 December 2010 / Accepted: 5 January 2011 /Published online: 21 January 2011

(C) The Author(s) 2011. This article is published with open access at Springerlink.com

\begin{abstract}
Prior residency advantages have been explained by an asymmetry between the 'owner' and the 'intruder' in fighting ability (resource-holding potential) or motivation (value asymmetry (VA)). Here, we tested for the extent of prior residence effects in individually tagged Atlantic salmon juveniles being released in two bouts (4 days apart) during spring along a natural stream, and recaptured 3 months later. A prior residency advantage was detected both in terms of body growth, energy density and male gonad size. As we controlled for effects of initial body size, which correlates with dominance, these findings are in accordance with the VA hypothesis. The growth advantage of first arrivals also increased with local shelter abundance in the stream, which can be expected if a higher resource value of the habitat results in a higher defence motivation. We also found a prior residence effect on spatial distribution, with the second arrivals within each release site being recaptured further downstream. No effect on apparent survival rates was found. The observed reduced growth and energy density may have fitness consequences for the second arrivals, both in terms of lower winter survival rates and later age at maturity. For mature male parr, both decreased body and gonad growth may give an additional disadvantage through reduced fertilization rates during
\end{abstract}

Communicated by K. Lindström

E. Kvingedal $\cdot$ S. Einum

Norwegian Institute for Nature Research,

Tungasletta 2,

NO-7485 Trondheim, Norway

\section{S. Einum $(\bowtie)$}

Centre for Conservation Biology, Department of Biology,

Norwegian University of Science and Technology,

Trondheim, Norway

e-mail: sigurd.einum@bio.ntnu.no breeding. These costs may help to explain the tendency for stationary behaviour of stream salmonids, as the potential benefits of moving into less crowded areas would be reduced by the risk of becoming an intruder. Prior residence effects may therefore have influenced the evolution of movement behaviour in these organisms.

Keywords Intraspecific competition · Dispersal · Density dependence $\cdot$ Social dominance $\cdot$ Territorial contests

\section{Introduction}

The prior residence effect, where the first individual to inhabit a new habitat has an advantage in territory contests, has been found in a number of empirical studies (Bradbury and Vehrencamp 1998) and has received focus in theoretical analysis of asymmetric competition (e.g. Maynard Smith and Parker 1976; Enquist and Leimar 1987). The competitive advantage of the first arrivals ('owners') compared with later arriving individuals ('intruders') has mainly been explained by three different hypothesis (Maynard Smith and Parker 1976). Firstly, the uncorrelated asymmetry hypothesis proposes the existence of arbitrary conventions in settling contests. However, simple conventions such like 'owners' always win, are unlikely to be stable (Grafen 1987), and the current consensus is that this hypothesis does not perform well as an explanation of territorial behaviour (Kokko et al. 2006). Secondly, the hypothesis of resource-holding power (RHP) predicts that the owners win because they possess superior fighting characteristics through, e.g. larger body size, larger weapons or being more aggressive, and has received support in many animal species (review in Kokko et al. 2006). Finally, the hypothesis of value asymmetry (VA) predicts that the territory has a higher value for the owners and 
therefore makes them more motivated to defend it (Maynard Smith and Parker 1976). The higher ownership value might be due to invested energy in negotiation of territory boundaries (Eason and Hannon 1994) or the achievement of local experience of hiding places or food resources (Davies and Houston 1981). The VA hypothesis has received support by removal-replacement experiments, mainly in birds (e.g. Krebs 1982; Tobias 1997), but also in other animal groups (Englund and Olsson 1990; Johnsson and Forser 2002).

Stream-living juvenile salmonids are well suited for performing experiments relating to prior residency, and have therefore become important model organisms in this context. They are primarily territorial (although individuals may move among different patches through time, they usually defend a single spatial location at any given time (Steingrimsson and Grant 2008)), and both the RHP and the VA hypothesis may contribute to asymmetries in competition for territories. Behavioural observations suggest strong body size effects on competitive abilities (Abbott et al. 1985; Cutts et al. 1999a), but prior residence effects have also been reported under artificial and/or enclosed settings when controlling for differences in body size or dominance either by the experimental design or statistically (e.g. Cutts et al. 1999a; O'Connor et al. 2000; Bohlin et al. 2002; Johnsson and Forser 2002; Harwood et al. 2003; Metcalfe et al. 2003; Brännäs et al. 2004). Yet, despite all this interest, it remains to be shown how prior residency may contribute to competitive asymmetries in natural streams under conditions where intruders may disperse to unoccupied areas. This is crucial to understand the role of competitive asymmetries for wild populations, and predictions based solely on artificial settings may also be problematic because dominance relationships determined under such conditions may not translate into competitive advantages in nature (Martin-Smith and Armstrong 2002).

In the present study, we test for prior residence effects on growth, energy density, incidence of maturation and gonadal investment, survival and spatial distribution of hatchery reared Atlantic salmon yearlings released at two different times (separated by 4 days) in a natural stream. Maturation and gonadal investment is only relevant for males, as no maturation occurs in females prior to sea migration. We also evaluated up to what extent the results were consistent with the VA or RHP hypotheses. The resources of a territory may influence the value asymmetry between owners and intruders. Often a territory owner has more knowledge of the resources, and if so, sequential assessment games predict that with increasing territory quality, the owners are more motivated for fighting and win more contests (Enquist and Leimar 1987; Englund and Olsson 1990). Thus, we predict the residence advantage to increase with increasing quality of available territories under the VA hypothesis. Shelter availability
(Finstad et al. 2009) is known to influence growth and emigration rates of stream salmonids, and was therefore used as a measure of the quality of potential territories. According to the RHP hypothesis, the ownership of territories will be set by the individuals fighting capability and not the order of arrival per se. Hence, this alternative hypothesis predicts no difference in performance related to the release group but in performance to depend on initial body size as an indicator of dominance. Since we do not know the actual residential status of the juveniles, we use the terms 'primaries' and 'secondaries' for the individuals in the first- and secondrelease group, respectively (O’Connor et al. 2000).

\section{Material and methods}

The study was conducted in the Stream Osalandsbekken, a small tributary to the River Imsa in southwestern Norway. The stream has a resident brown trout population, but no naturally occurring Atlantic salmon due to a barrier preventing upwards migration from the River Imsa. One thousand one hundred eighty 1 year-old captively bred Imsa salmon were pit-tagged and length measured during 8-14 June. To create a range of local densities, the fish were divided into nine groups with 20 to 250 individuals in each (Table 1). Half of the individuals in each group (denoted 'primaries' in the following text) were released in Stream Osalandsbekken on 10 June, while the remaining fish (denoted 'secondaries') were released 4 days later. We transported the salmon parr in oxygenated water to nine release sites situated $150 \mathrm{~m}$ apart. Before being released, the fish were kept in enclosures in the stream for 3-4 h of habituation.

Recapturing was performed by electrofishing in the period 5-8 September. The stream was divided into 50-m sections, the first one starting $200 \mathrm{~m}$ below the lowest release site and the last one at an impassable waterfall $50 \mathrm{~m}$ above the uppermost release site. Depending on fish abundance and catchability, two to four electrofish passes were performed in each section. A total of 540 fish (46\%) of the released fish were recaptured (Table 1). Brown trout captured during electrofishing were length measured before being released back into the stream. Recaptured salmon were killed before transportation on ice to the lab for length and weight measurements. Thereafter, the fish were frozen for later determination of sex and measurements of gonadal and somatic dry $\left(48 \mathrm{~h}, 70^{\circ} \mathrm{C}\right)$ tissue weight.

Shelter abundance (number of interstitial spaces, $>3 \mathrm{~cm}$ deep) was measured using a $13-\mathrm{mm}$ tube in ten $0.25 \mathrm{~m}^{2}$ squares within each 50-m section according to the method described in Finstad et al. (2007). The squares were regularly spaced along each section, and randomly placed relative to the width of the stream. 
Table 1 Numbers and initial length (mean $\pm \mathrm{SD}$ ) of yearling Atlantic salmon released into the Stream Osalandsbekken and the corresponding recaptured number of fish, given separately for the first- and second-release group

\begin{tabular}{lcllc}
\hline Station & $\begin{array}{l}\text { Numbers released } \\
\text { (first }+ \text { second group) }\end{array}$ & \multicolumn{2}{l}{ Initial length $(\mathrm{mm})$} & $\begin{array}{c}\text { Numbers recaptured } \\
\text { (first }+ \text { second group) }\end{array}$ \\
\cline { 3 - 4 } & First & Second & \\
\hline 1 & $34+35$ & $111.6( \pm 15.6)$ & $113.4( \pm 11.1)$ & $21+14$ \\
2 & $20+20$ & $110.5( \pm 13.5)$ & $118.0( \pm 13.5)$ & $10+14$ \\
3 & $95+95$ & $112.3( \pm 13.0)$ & $118.6( \pm 11.2)$ & $39+36$ \\
4 & $10+10$ & $109.7( \pm 15.7)$ & $118.8( \pm 14.8)$ & $4+6$ \\
5 & $125+125$ & $115.8( \pm 13.5)$ & $115.8( \pm 11.3)$ & $72+69$ \\
6 & $80+80$ & $112.1( \pm 14.9)$ & $119.9( \pm 10.9)$ & $45+48$ \\
7 & $50+50$ & $112.6( \pm 12.3)$ & $114.1( \pm 14.6)$ & $19+17$ \\
8 & $65+65$ & $109.0( \pm 14.9)$ & $119.9( \pm 12.3)$ & $33+21$ \\
9 & $110+110$ & $115.7( \pm 11.4)$ & $118.7( \pm 10.8)$ & $34+38$ \\
\hline
\end{tabular}

\section{Density estimates}

Local population densities were estimated for each section by the Zippin procedure, based on successive removal of fish during electrofish passes (Bohlin et al. 1989). In sections were the total catch was less than 16 individuals (ten out of 25 sections), densities were estimated from average catchability (i.e. estimated catchability from the other sections). Local densities were also estimated for resident trout (underyearling and overyearling) and salmon underyearlings released in connection with another study. However, since competition between cohorts or species was not the topic of this study, and neither the trout density or salmon underyearling density had any impact on the statistical models (see below), only analyses based on salmon parr densities are included.

\section{Statistical analyses}

The effect of prior residency on (1) achieved body size, (2) energy status and (3) gonad investment were analyzed using linear mixed-effects models (LMM), with recapture section as a random factor. A model simplification approach was followed, starting with a beyond optimal model, which included fixed effects and interactions considered to be of potential significance in the optimal model (Zuur et al. 2009). Non-significant fixed effect parameters were sequentially removed from the baseline model based on log-likelihood tests of maximum likelihood models according to the recommended procedure of Zuur et al. (2009). Exploration of the residuals given by the starting models indicated heteroscedastisity; hence, a variance function for each model was added to stabilize the residuals (Zuur et al. 2009).

1. For achieved body length (final size), the fixed part of the starting model was given by final length initial length $+(\text { initial length })^{2}+$ group + maturity + salmon parr density + shelter density + maturity $\times$ initial length + group $\times$ salmon parr density + group $\times$ shelter density. Maturity (i.e. mature or not) was included to allow for costs of gonad investment in mature males. The squared initial length was included due to a curved relationship between final and initial body length. Decreasing residuals with increasing initial length was modelled by including a power of variance function with initial length as covariate.

2. Energy density in fish is closely correlated with the dry to wet body weight ratio (Hartman and Brandt 1995; Wuenschel et al. 2006; Hartman and Margraf 2008). Hence, energy status at recapture was modelled using total dry body weight as response variable while controlling for wet final body weight. The fixed part of the starting model was given by: dry body weight maturity $\times$ wet body weight + group $\times$ salmon parr density + group $\times$ shelter density. Here, the error variance increased with final body weight; hence, a variance function with wet body weight as covariate was included.

3. To test if fecundity of mature males differed between residency groups, gonad dry weight was used as response variable while controlling for initial body length. The starting model was expressed as dry gonad weight initial length + (initial length $)^{2}+$ group + salmon parr density + shelter density + group $\times$ initial length + group $\times$ salmon parr density + group $\times$ shelter density. Initial analysis showed that variance increased with initial length and decreased with local fish density, thus a variance function including both these variables as covariates was included. We also tested whether the release order affected gonadal investment, by analysing gonad dry weight relative to total dry body weight (somatic plus gonad tissue). This starting model was expressed as dry gonad weight $\sim$ dry body weight + group + salmon parr density + shelter density + group $\times$ dry body weight + group $\times$ salmon parr density + group $\times$ shelter density. Variance increased with body 
size, thus a variance function with dry body weight as a covariate was included.

The effect of prior residency on (4) dispersal distance, (5) apparent survival, and (6) probability of maturation was tested by stepwise simplification of generalized linear mixed models (GLMM) using a Poisson distribution for the dispersal model and a binomial distribution for the survival and maturation probability model. In these three models, release station was entered as a random factor. The starting GLMMs included initial body length, release group and released number of fish as fixed effects.

4. Dispersal was analyzed using relative recapture section within each release station as response variable, i.e. the lowermost recaptured fish from each release site was given section number one and the remaining recapture sections were numbered relative to the lowest one. The fixed part of the model was given by: relative dispersal initial length + group + number released + group $\times$ initial length. An interaction between group and released number could not be included, as this prevented convergence. However, analysis by generalized linear models (GLM, i.e. excluding random effects) did not indicate any significant interactions.

5. We used recapture as a measure of apparent survival, under the assumption that recapture rate is proportional to survival rate. We started with a model with the fixed part given by: apparent survival initial length + group + number released. Interactions could not be included as the model would not converge. Analysis by GLM gave no indications of interactions between group and released number of fish or initial size, though there might be a possible interaction between initial length and released number of fish (stepwise deletion test with binomial distribution, $Z=-3.4 ; P=0.07$ ). This interaction was of no interest in this study, however.

6. Probablility of maturation was analysed based on data on recaptured male fish. The fixed part of the starting model was given by maturation $\sim$ initial length + group + number released + group $\times$ number released. In this model an interaction between group and initial length could not be included due to convergence problems, but again, analysis by GLM (i.e. excluding random effects) did not indicate any significant interactions.

All statistical modelling was performed in $\mathrm{R}(\mathrm{R}$ Development Core Team, 2009) using the function lme in the nlme package (Pinheiro et al. 2009) for the linear mixed-effects models and lmer in the lme4 package (Bates and Maechler 2009) for the generalized linear mixed models.

\section{Results}

Body size and energy content

Simplification of the LME model of final body length as response variable while controlling for initial body length, revealed a significant negative effect of increased population density and maturation (Table 2a). In addition, there was a significant interaction between group and shelter density, with a larger positive effect of shelter availability for the first arrivals (Table 2a). Over the whole range of observed shelter density, the estimated length increment was larger for primaries than for secondaries (Fig. 1). Intracohort competition, in terms of local population density, had a negative effect on achieved body size (Table 2a), but did not differ significantly between primaries and secondaries (likelihood ratio $=0.92 ; P=0.34$ ).

When we modelled energy content by using dry weight as response variable and final wet weight as a covariate, group identity had a significant effect (Table 2b). For a given final body weight, the dry weight was higher for primaries than for secondaries. There was also an interaction between maturity status and final body weight, with mature male parr showing a shallower slope between final wet and dry weight (Table $2 b$ ). There was however no significant interactions between residence status and maturity (likelihood ratio $=1.8 ; P=0.18$ ). This, combined with the finding that the probability of maturation did not differ between the two groups (see below), indicates that the cost of maturation was not significantly larger for the secondaries.

Probability of maturation, gonad size and gonadal investment

Based on 169 recaptured males, only 17 were immature and 13 of these were primaries. However, GLMM simplification of the starting model for maturation probability did not give significant effects of release order $\left(\chi^{2}=1.1 ; P=0.3\right)$, but an effect of initial size $\left(\chi^{2}=30.5 ; P<0.001\right)$ and the number of fish in the release groups $\left(\chi^{2}=5.7 ; P=0.02\right)$. The resulting model for maturity probability, given in logit units, was $-8.56( \pm 2.45 \quad \mathrm{SE})+0.13 \quad( \pm 0.03 \quad \mathrm{SE}) \times$ initial length $-0.012( \pm 0.005 \mathrm{SE}) \times$ released number. When controlling for initial length, the best model for dry gonad weight, revealed a significant interaction effect of shelter density and release order (Table 2c). Except for the lack of a significant effect of salmon parr density (likelihood ratio $=$ 2.6; $P=0.10$ ), the model coincides with the model for final body length (Table 2a). However, when looking at gonadal investment relative to achieved size, model simplification did not reveal any significant effect of parr density (likelihood ratio $=0.4 ; P=0.53$ ), shelter density (likelihood 
Table 2 The best mixed-effects models of (a) final body length (mm), $N=534$, (b) dry body weight (g), $N=532$, and (c) dry gonad weight $(\mathrm{g}), N=253$, following stepwise deletion tests

\begin{tabular}{llcrc}
\hline & Parameter & Value \pm SE & $t$ & $P$ \\
\hline Final body length & Intercept & $101.9 \pm 10.6$ & 9.6 & $<0.001$ \\
& Mature & $-1.4 \pm 0.3$ & -4.5 & $<0.001$ \\
& Initial length $(\mathrm{mm})$ & $-0.51 \pm 0.19$ & -2.7 & 0.007 \\
& Initial length ${ }^{2}\left(\mathrm{~mm}^{2}\right.$ ) & $0.006 \pm 0.001$ & 7.1 & $<0.001$ \\
& Salmon density (ind. ${ }^{-2}$ ) & $-10.3 \pm 3.3$ & -3.1 & 0.005 \\
& Shelter density (shelters $\mathrm{m}^{-2}$ ) & $0.19 \pm 0.06$ & 3.2 & 0.004 \\
& Group (second) & $0.34 \pm 0.86$ & 0.4 & 0.70 \\
& Shelter density $\times$ group (second) & $-0.079 \pm 0.039$ & -2.0 & 0.044 \\
& Intercept & $-0.66 \pm 0.03$ & -20.7 & $<0.001$ \\
& Mature & $0.15 \pm 0.04$ & 3.9 & $<0.001$ \\
& Final wet weight $(\mathrm{g})$ & $0.28 \pm 0.002$ & 165 & $<0.001$ \\
& Group (second) & $-0.045 \pm 0.011$ & -4.1 & $<0.001$ \\
& Mature $\times$ final weight & $-0.019 \pm 0.002$ & -7.9 & $<0.001$ \\
Dry gonad weight & Intercept & $0.82 \pm 0.35$ & 2.32 & 0.02 \\
& Initial length (mm) & $-0.020 \pm 0.007$ & -3.0 & 0.003 \\
& Initial length ${ }^{2}$ (mm ${ }^{2}$ ) & $1.3 \times 10^{-4} \pm 0.3 \times 10^{-4}$ & 4.3 & $<0.001$ \\
& Shelter density (shelters ${ }^{-2}$ ) & $0.007 \pm 0.002$ & 4.2 & $<0.001$ \\
& Group (second) & $0.05 \pm 0.03$ & 1.6 & 0.11 \\
& Shelter density $\times$ group (second) & $-0.005 \pm 0.001$ & -3.1 & 0.002 \\
\hline & & & &
\end{tabular}

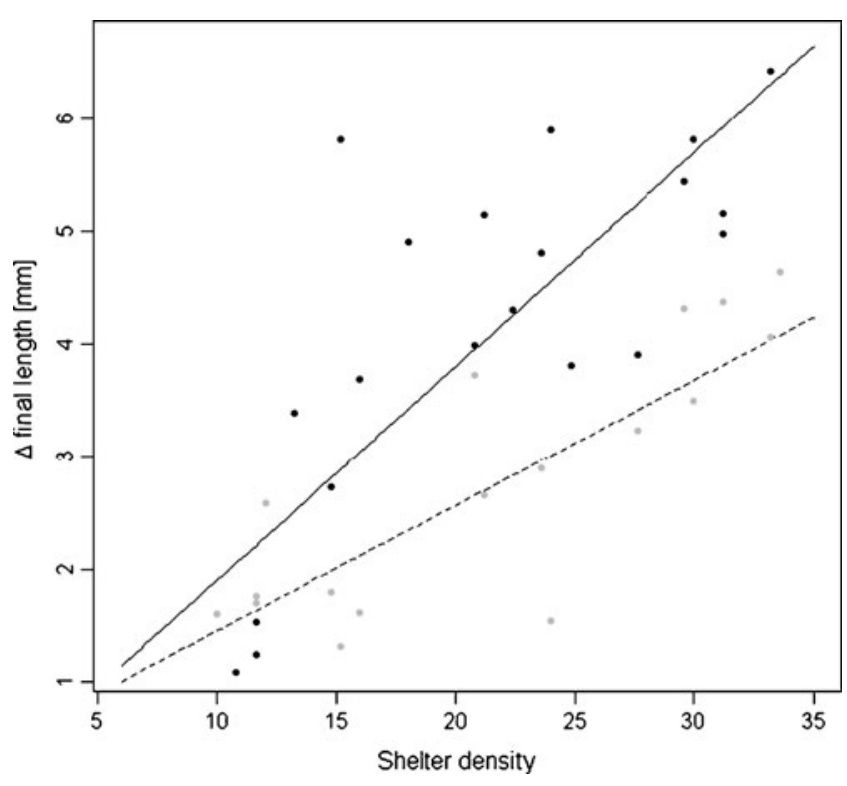

Fig. 1 Modelled increment in Atlantic salmon parr final body length given by shelter density (shelters $\mathrm{m}^{-2}$ ) and prior residency (solid line primaries and dashed line secondaries) in the Stream Osalandsbekken. Plotted values show section average values of final length after removing the estimated effect of initial size, maturity and salmon parr density for primaries (black) and secondaries (grey). To reduce the variance due to low sample size, only sections with more than than two individuals within a residence class are included in the plots (i.e. two and five sections sections excluded in the plot of primaries and secondaries, respectively) ratio $=1.6 ; P=0.21$ ), or release order (likelihood ratio $=1.5$; $P=0.22)$. The best LMM for dry gonad weight included dry body weight only (dry gonad weight $=-0.066( \pm 0.014 \mathrm{SE})$ $+0.112( \pm 0.003 \mathrm{SE}) \times$ dry body weight $)$.

Dispersal and survival

Model simplification of the starting GLMM for relative position of recaptured salmon parr revealed a significant effect of release group ( $\chi^{2}=18.4 ; P<0.001$; Fig. 2$)$, but no effect of released fish number $\left(\chi^{2}=0.03 ; P=0.9\right)$ or initial body size $\left(\chi^{2}=0.75 ; P=0.4\right)$. The fixed effect part of the best model was: $\ln$ relative section $=0.93( \pm 0.05 \mathrm{SE})-0.25( \pm 0.06$ $\mathrm{SE}) \times$ second group, which after back-transformation gave expected positions of 2.53 and 1.98 sections for first and second arrivals, respectively (Fig. 2), indicating that the second arrivals were more likely to be found further downstream. With regard to survival, only initial length had an effect $\left(\chi^{2}=7.7 ; P=0.006\right)$, while there was no effect of release group $\left(\chi^{2}=0.15 ; P=0.7\right)$ or released number of fish $\left(\chi^{2}=0.22 ; P=0.6\right)$. The fixed effects part of the resulting GLMM for apparent survival given in logit units was: 1.31 $( \pm 0.55 \mathrm{SE})-0.013( \pm 0.004 \mathrm{SE}) \times$ initial length; hence, there was a lower apparent survival for larger individuals.

\section{Discussion}

In this study we find evidence for a prior residence advantage (body growth, male gonad size and energy 
1st release group

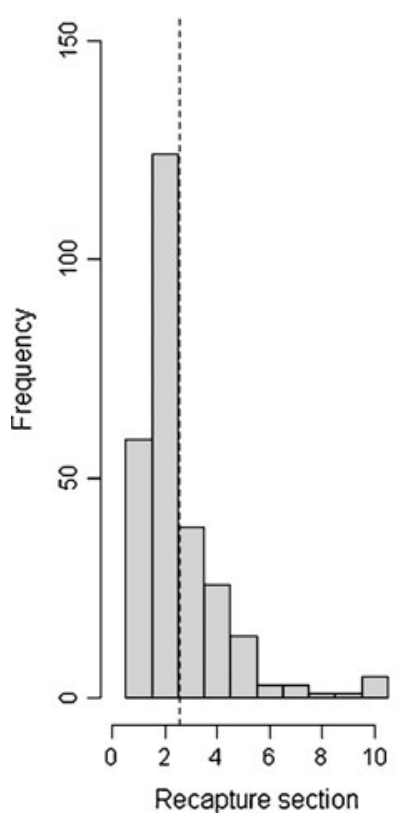

2nd release group

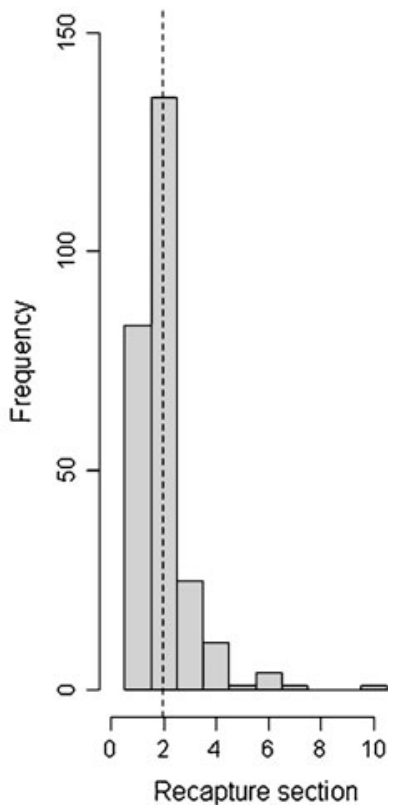

Fig. 2 Spatial distribution of recaptured salmon parr from the firstand second-release groups in the Stream Osalandsbekken. Recapture section denotes the number of sections upstream from the lowermost recapture $($ section=1) for each release station. Expected position for each group, given by the best model, is indicated with dashed lines

density) between groups of Atlantic salmon juveniles arriving in a natural stream four days apart. As we are controlling for body size, which is closely linked to dominance (Elliott 1990; Cutts et al. 1999b), these findings support the VA hypothesis, i.e. that the first arriving individuals gain a competitive advantage caused solely by being resident. Furthermore, the advantage of arriving first appears to be strongly linked to the abundance of shelters. Actually, according to the statistical model (Table 2a, c), in the absence of shelters no advantage of arriving first is expected (no main effect of group). Larger competitive advantage of ownership in structurally complex territories of fish has previously been demonstrated in aquarium experiments (Nijman and Heuts 2000). In brown trout juveniles, competition experiments have shown that the level of aggression toward an intruder depends on the owner's territory quality, either in terms of cover presence (Johnsson et al. 2004) or in terms of individual preferences (Johnsson et al. 2000). Evidence for increased fighting effort and more wins among owners with increasing resource value, has also been reported in empirical studies of other animals (e.g. Riechert 1984; Otto 1987; Dearborn 1998; Elwood et al. 1998). Hence, our findings are in accordance with expected growth consequences following from the observed behaviour in competition experiments or field studies with varying resource values.

Interestingly, despite the effect of population density on habitat quality as measured by growth rates, it did not influence the effect of prior residency. This may appear to be in conflict with predictions from the VA hypothesis, since density influences habitat quality and hence presumably territory quality. However, a critical assumption for the value asymmetry to occur, is that an increase in resource value increases the motivation of the owner more than the intruder. This assumption has often been linked to information asymmetry (Enquist and Leimar 1987; Bradbury and Vehrencamp 1998), such that the perceived value of a territory increases more for a certain increase in territory quality for the owner than for the intruder. Changes in density may not represent such information asymmetry if the experienced density (and hence the quality of any given territory) is independent of whether you are an owner or intruder. The change in the perceived relative value of a certain territory with changing density would then be independent of timing of arrival to an area, and this may explain the lack of density effects in the present study.

Higher growth rates of first arrivals are in accordance with previous findings in juvenile stream salmonids based on experiments in artificial environments (Huntingford and Garcia de Leániz 1997; Cutts et al. 1999a; Deverill et al. 1999; O’Connor et al. 2000; Harwood et al. 2003; Brännäs et al. 2004) and a field experiment with restricted dispersal during settlement (Bohlin et al. 2002). Increased energy density due to prior residency has to our knowledge not previously been reported, neither in fish nor other animals, but is consistent with higher growth rates. The higher growth rates and energy densities in residents may be explained by occupation of better territories, either in terms of superior feeding sites resulting in higher feeding rates and/or better shelter availability which reduce energy expenditure (Finstad et al. 2007). In addition, a lower proportion of the second arrivals may have been able to establish territories. In an artificial stream experiment where groups of juvenile Atlantic salmon were released in four waves, Huntingford and Garcia de Leániz (1997) found that the earlier waves had higher settlement rates. A similar effect was observed by Cutts et al. (1999a), who reported that among Atlantic salmon juveniles being released into an artificial stream, half of the first arriving ones obtained distinct territories, whereas virtually none in the subsequent release groups did. However, in both these experiments the available area of settlement was restricted and the fish that did not establish a territory were either recaptured in a downstream trap (Huntingford and Garcia de Leániz 1997) or confined to a restricted area (Cutts et al. 1999a). In our study, on the other hand, the salmon juveniles were able to disperse. Hence, rather than becoming floaters or migrating out of the system, the secondaries not able or willing to 
outcompete the first arrivals, could settle outside the already occupied area. Our findings of a more downstream positioning of the second group do indicate this.

Even though our results of a prior residence effect on growth and energy, as well as the increased effect with increasing shelter availability, are according to predictions from the VA hypothesis, these results cannot entirely exclude the RHP hypothesis. This is because ownership status may not only affect value asymmetries and hence fighting motivation, but also the RHP (Parker 1974; Maynard Smith and Parker 1976; Bradbury and Vehrencamp 1998; see Table A1 in Kokko et al. 2006). One potential mechanism for this is that knowledge of the territory increases fighting abilities. In salmon juveniles, a complex environment may require more attention towards processing visual information, and knowing a location well may enable a resident to focus more of its attention towards a competitor. However, even if we cannot exclude the possibility of ownership enhanced RHP based on our data, the findings of prior residence effects even in experimental environments with very low complexity (i.e. artificial tanks, (Brännäs et al. 2004) suggest owner benefits at least partly can be attributed to increased fighting motivation.

We did not find evidence for a prior residence effect on survival rates. Hence, the advantage of settlement in more valuable areas, either in terms of shelter or food availability, did not seem to reduce predation or starvation risk during these three summer months. However, higher growth rates and energy densities in prior residents of Atlantic salmon juveniles may have indirect consequences for fitness. For example, the growth rate of Atlantic salmon juveniles in autumn determines whether they will metamorphose into the smolt phase and migrate to sea the following spring or will stay in freshwater for one more year (Thorpe 1977; Metcalfe and Thorpe 1992; Thorpe et al. 1998). Furthermore, large body size in autumn (e.g. Post and Evans 1989; Johnson and Evans 1991; Miranda and Hubbard 1994; but see Hendry et al. 2003; Carlson et al. 2008), as well as stored energy levels (Finstad et al. 2004), are considered advantageous for winter survival in fish. Hence, being an intruder into an already occupied area may have negative impact on fitness both through reduced survival rate in winter and greater absolute mortality for juveniles due to delayed smolting.

In contrast to the lack of effect of prior residence on survival, we did find that survival rates decreased with increasing initial body size. However, since initial body size was not manipulated, we cannot distinguish between effects of body size per se and innate variation in growth rate. It may well be that traits providing rapid growth in the hatchery, and hence a large initial size among our released fish, are disadvantageous for survival in the wild. Rapid growth of salmonid juveniles in hatchery environments is provided by high metabolic rates and associated dominance status (Metcalfe et al. 1989, 1995), and a high metabolic rate may be negatively correlated with survival in the wild (Álvarez and Nicieza 2005). Furthermore, manipulations of growth rates in the wild using growth hormone implants have been shown to cause increased movement activity (Sundt-Hansen et al. 2009), and this may cause increased predation mortality due to greater predator exposure (Lankford et al. 2001; Biro et al. 2004; Stoks et al. 2005).

We did not find a prior residency effect on the probability of maturation, which is in accordance with studies suggesting that the decision to mature is made during the spring (Rowe and Thorpe 1990, Rowe et al. 1991), i.e. prior to our releases. However, we did find that the prior residence advantage on body growth also translated into larger gonad size. To our knowledge, this has not been studied previously. As sperm is considered to be a limited resource for precocious males during mating (Thomaz et al. 1997), larger gonad sizes (and thereby more sperm) for larger individuals may lead to higher fertilization rates. During spawning the larger male parr may also have an advantage by the size dependent dominance hierarchy giving them positions closer to the spawning females (Myers and Hutchings 1987). Hence among male parr, the growth advantage given by first arrival may not only affect survival probabilities, but also increase fertilization rates.

The cost of being a secondary may help to explain the stationary behaviour of juvenile stream salmonids, as suggested by Bohlin et al. (2002). Both the present study and other recent studies show that local population density affects juvenile salmonid growth rates, and that movements are insufficient to homogenize densities and growth rates over space (Jenkins et al. 1999; Bohlin et al. 2002; Einum et al. 2006; Einum et al. 2008). The prior residence effect may contribute to reducing potential benefits of moving away from crowded areas due to the competitive disadvantage of being an intruder, and may therefore have shaped the evolution of movement behaviour in these organisms.

Acknowledgements We thank landowners for permission to undertake this work, L. Sundt-Hansen, A. G. Finstad and the staff at NINA Research Station for technical and field assistance and N. Metcalfe and one anonymous reviewer for helpful comments. Financial support was provided by the Norwegian Research Council. The study was conducted according to national regulations for the treatment and welfare of experimental animals. This study was performed in compliance with the Norwegian legislation on animal care and experimentation. The authors declare that they have no conflicts of interest.

Open Access This article is distributed under the terms of the Creative Commons Attribution Noncommercial License which permits any noncommercial use, distribution, and reproduction in any medium, provided the original author(s) and source are credited. 


\section{References}

Abbott JC, Dunbrack RL, Orr CD (1985) The interaction of size and experience in dominance relationships of juvenile steelhead trout (Salmo gairdneri). Behaviour 92:241-253

Álvarez D, Nicieza AG (2005) Is metabolic rate a reliable predictor of growth and survival of brown trout (Salmo trutta) in the wild? Can J Fish Aquat Sci 62:643-649

Bates D, Maechler M (2009) lme4: Linear mixed-effects models using S4 classes. R package version 0.999375-32

Biro PA, Abrahams MV, Post JR, Parkinson EA (2004) Predators select against high growth rates and risk-taking behaviour in domestic trout populations. P Roy Soc Lond B Bio 271:2233-2237

Bohlin T, Hamrin S, Heggberget TG, Rasmussen G, Saltveit SJ (1989) Electrofishing - theory and practice with special emphasis on salmonids. Hydrobiologia 173:9-43

Bohlin T, Sundström LF, Johnsson JI, Höjesjö J, Pettersson J (2002) Density-dependent growth in brown trout: effects of introducing wild and hatchery fish. J Anim Ecol 71:683-692

Bradbury JW, Vehrencamp SL (1998) Principles of animal communication. Sinauer Associates, Sunderland

Brännäs E, Jonsson S, Brännäs K (2004) Density-dependent effects of prior residence and behavioural strategy on growth of stocked brown trout (Salmo trutta). Can J Zool 82:1638-1646

Carlson SM, Olsen EM, Vøllestad LA (2008) Seasonal mortality and the effect of body size: a review and an empirical test using individual data on brown trout. Funct Ecol 22:663-673

Cutts CJ, Brembs B, Metcalfe NB, Taylor AC (1999a) Prior residence, territory quality and life-history strategies in juvenile Atlantic salmon (Salmo salar L.). J Fish Biol 55:784-794

Cutts CJ, Metcalfe NB, Taylor AC (1999b) Competitive asymmetries in territorial juvenile Atlantic salmon, Salmo salar. Oikos 86:479-486

Davies NB, Houston AI (1981) Owners and satellites: the economics of territory defence in the pied wagtail, Motacilla alba. J Anim Ecol 50:157-180

Dearborn DC (1998) Interspecific territoriality by a rufous-tailed hummingbird (Amazilia tzacatl): effects of intruder size and resource value. Biotropica 30:306-313

Deverill JI, Adams CE, Bean CW (1999) Prior residence, aggression and territory acquisition in hatchery-reared and wild brown trout. J Fish Biol 55:868-875

Eason P, Hannon SJ (1994) New birds on the block-new neighbors increase defensive costs for territorial-male willow ptarmigan. Behav Ecol Sociobiol 34:419-426

Einum S, Sundt-Hansen L, Nislow KH (2006) The partitioning of density-dependent dispersal, growth and survival throughout ontogeny in a highly fecund organism. Oikos 113:489-496

Einum S, Nislow KH, Mckelvey S, Armstrong JD (2008) Nest distribution shaping within-stream variation in Atlantic salmon juvenile abundance and competition over small spatial scales. J Anim Ecol 77:167-172

Elliott JM (1990) Mechanisms responsible for population regulation in young migratory trout, Salmo trutta. 3. The role of territorial behavior. J Anim Ecol 59:803-818

Elwood RW, Wood KE, Gallagher MB, Dick JTA (1998) Probing motivational state during agonistic encounters in animals. Nature 393:66-68

Englund G, Olsson TI (1990) Fighting and assessment in the netspinning caddis larva Arctopsyche ladogensis - a test of the sequential assessment game. Anim Behav 39:55-62

Enquist M, Leimar O (1987) Evolution of fighting behavior-the effect of variation in resource value. J Theor Biol 127:187-205

Finstad AG, Ugedal O, Forseth T, Naesje TF (2004) Energy-related juvenile winter mortality in a northern population of Atlantic salmon (Salmo salar). Can J Fish Aquat Sci 61:2358-2368
Finstad AG, Einum S, Forseth T, Ugedal O (2007) Shelter availability affects behaviour, size-dependent and mean growth of juvenile Atlantic salmon. Freshw Biol 52:1710-1718

Finstad AG, Einum S, Ugedal O, Forseth T (2009) Spatial distribution of limited resources and local density regulation in juvenile Atlantic salmon. J Anim Ecol 78:226-235

Grafen A (1987) The logic of divisively asymmetric contests - respect for ownership and the desperado effect. Anim Behav 35:462-467

Hartman KJ, Brandt SB (1995) Estimating energy density of fish. Trans Am Fish Soc 124:347-355

Hartman KJ, Margraf FJ (2008) Common relationships among proximate composition components in fishes. J Fish Biol 73:2352-2360

Harwood AJ, Griffiths SW, Metcalfe NB, Armstrong JD (2003) The relative influence of prior residency and dominance on the early feeding behaviour of juvenile Atlantic salmon. Anim Behav 65:1141-1149

Hendry AP, Letcher BH, Gries G (2003) Estimating natural selection acting on stream-dwelling Atlantic salmon: implications for the restoration of extirpated populations. Cons Biol 17:795-805

Huntingford FA, Garcia de Leániz CG (1997) Social dominance, prior residence and the acquisition of profitable feeding sites in juvenile Atlantic salmon. J Fish Biol 51:1009-1014

Jenkins TM, Diehl S, Kratz KW, Cooper SD (1999) Effects of population density on individual growth of brown trout in streams. Ecology 80:941-956

Johnson TB, Evans DO (1991) Behavior, energetics, and associated mortality of young-of-the-year white perch (Morone americana) and yellow perch (Perca flavescens) under simulated winter conditions. Can J Fish Aquat Sci 48:672-680

Johnsson J, Forser A (2002) Residence duration influences the outcome of territorial conflicts in brown trout (Salmo trutta). Behav Ecol Sociobiol 51:282-286

Johnsson JI, Carlsson M, Sundstrom LF (2000) Habitat preference increases territorial defence in brown trout (Salmo trutta). Behav Ecol Sociobiol 48:373-377

Johnsson JI, Rydeborg A, Sundstrom LF (2004) Predation risk and the territory value of cover: an experimental study. Behav Ecol Sociobiol 56:388-392

Kokko H, Lopez-Sepulcre A, Morrell LJ (2006) From hawks and doves to self-consistent games of territorial behavior. Am Nat 167:901-912

Krebs JR (1982) Territorial defence in the great tit (Parus major): do residents always win? Behav Ecol Sociobiol 11:185-194

Lankford TE, Billerbeck JM, Conover DO (2001) Evolution of intrinsic growth and energy acquisition rates. II. Trade-offs with vulnerability to predation in Menidia menidia. Evolution 55:1873-1881

Martin-Smith KM, Armstrong JD (2002) Growth rates of wild streamdwelling Atlantic salmon correlate with activity and sex but not dominance. J Anim Ecol 71:413-423

Maynard Smith J, Parker GA (1976) The logic of asymmetric contests. Anim Behav 24:159-175

Metcalfe NB, Thorpe JE (1992) Early predictors of life-history eventsthe link between $1 \mathrm{st}$ feeding date, dominance and seaward migration in Atlantic salmon, Salmo salar L. J Fish Biol 41:93-99

Metcalfe NB, Huntingford FA, Graham WD, Thorpe JE (1989) Early social status and the development of life-history strategies in Atlantic salmon. P Roy Soc Lond B Bio 236:7-19

Metcalfe NB, Taylor EB, Thorpe JE (1995) Metabolic rate, social status and life-history strategies in Atlantic salmon. Anim Behav 49:431-436

Metcalfe NB, Valdimarsson SK, Morgan IJ (2003) The relative roles of domestication, rearing environment, prior residence and body size in deciding territorial contests between hatchery and wild juvenile salmon. J Appl Ecol 40:535-544 
Miranda LE, Hubbard WD (1994) Length-dependent winter survival and lipid-composition of age-0 largemouth bass in Bay Springs reservoir, Mississippi. Trans Am Fish Soc 123:80-87

Myers RA, Hutchings JA (1987) Mating of anadromous Atlantic salmon, Salmo salar L., with mature male parr. J Fish Biol 31:143-146

Nijman V, Heuts BA (2000) Effect of environmental enrichment upon resource holding power in fish in prior residence situations. Behav Process 49:77-83

O'Connor KI, Metcalfe NB, Taylor AC (2000) The effects of prior residence on behavior and growth rates in juvenile Atlantic salmon (Salmo salar). Behav Ecol 11:13-18

Otto C (1987) Asymmetric competition for cases in Agrypnia pagetana (Trichoptera) larvae. Oikos 48:253-257

Parker GA (1974) Assessment strategy and the evolution of fighting behavior. J Theor Biol 47:223-243

Pinheiro J, Bates D, Debroy S, Sarkar D, The R Core Team (2009) nlme: linear and nonlinear mixed effects models. $\mathrm{R}$ package version 3.1-96

Post JR, Evans DO (1989) Size-dependent overwinter mortality of young-of-the-year yellow perch (Perca flavescens) - laboratory, in situ enclosure, and field experiments. Can J Fish Aquat Sci 46:1958-1968

R Development Core Team (2009) R: A language and environment for statistical computing. R Foundation for Statistical Computing, Vienna, Austria

Riechert SE (1984) Games spiders play. III. Cues underlying contextassociate changes in agonistic behaviour. Anim Behav 32:1-15

Rowe DK, Thorpe JE (1990) Suppression of maturation in male Atlantic salmon (Salmo salar L.) parr by reduction in feeding and growth during spring months. Aquaculture 86:291-313
Rowe DK, Thorpe JE, Shanks AM (1991) Role of fat stores in the maturation of male Atlantic salmon (Salmo salar) parr. Can J Fish Aquat Sci 48:405-413

Steingrimsson SO, Grant JWA (2008) Multiple central-place territories in wild young-of-the-year Atlantic salmon Salmo salar. J Anim Ecol 77:448-457

Stoks R, DeBlock M, Van De Mutter F, Johansson F (2005) Predation cost of rapid growth: behavioural coupling and physiological decoupling. J Anim Ecol 74:708-715

Sundt-Hansen L, Neregård L, Einum S, Höjesjö J, Björnsson BT, Hindar K, Økland F, Johnsson JI (2009) Growth enhanced brown trout show increased movement activity in the wild. Funct Ecol 23:551-558

Thomaz D, Beall E, Burke T (1997) Alternative reproductive tactics in Atlantic salmon: factors affecting mature parr success. P Roy Soc Lond B Bio 264:219-226

Thorpe JE (1977) Bimodal distribution of length of juvenile Atlantic salmon (Salmo salar L.) under artificial rearing conditions. J Fish Biol 11:175-184

Thorpe JE, Mangel M, Metcalfe NB, Huntingford FA (1998) Modelling the proximate basis of salmonid life-history variation, with application to Atlantic salmon, Salmo salar L. Evol Ecol 12:581-599

Tobias J (1997) Asymmetric territorial contests in the European robin: the role of settlement costs. Anim Behav 54:9-21

Wuenschel MJ, Jugovich AR, Hare JA (2006) Estimating the energy density of fish: the importance of ontogeny. Trans Am Fish Soc 135:379-385

Zuur AF, Ieno EN, Walker N, Saveliev AA, Smith GM (2009) Mixed effects models and extensions in ecology with R. Springer, New York 